\title{
Anodic Dissolution of API X70 Pipeline Steel in Arabian Gulf Seawater after Different Exposure Intervals
}

\author{
El-Sayed M. Sherif ${ }^{1,2}$ and Abdulhakim A. Almajid ${ }^{1}$ \\ ${ }^{1}$ Department of Mechanical Engineering, College of Engineering, King Saud University, P.O. Box 800, Riyadh 11421, Saudi Arabia \\ ${ }^{2}$ Electrochemistry and Corrosion Laboratory, Department of Physical Chemistry, National Research Centre (NRC), Dokki, \\ Giza 12622, Egypt \\ Correspondence should be addressed to El-Sayed M. Sherif; esherif@ksu.edu.sa
}

Received 3 September 2013; Revised 7 February 2014; Accepted 18 February 2014; Published 25 March 2014

Academic Editor: Hakan Arslan

Copyright (C) 2014 E.-S. M. Sherif and A. A. Almajid. This is an open access article distributed under the Creative Commons Attribution License, which permits unrestricted use, distribution, and reproduction in any medium, provided the original work is properly cited.

\begin{abstract}
The anodic dissolution of API X70 pipeline steel in Arabian Gulf seawater (AGSW) was investigated using open-circuit potential (OCP), electrochemical impedance spectroscopy (EIS), cyclic potentiodynamic polarization (CPP), and current-time measurements. The electrochemical experiments revealed that the X70 pipeline steel suffers both general and pitting corrosion in the AGSW solution. It was found that the general corrosion decreases as a result of decreasing the corrosion current density $\left(j_{\text {corr }}\right)$, corrosion rate $\left(R_{\text {corr }}\right)$ and absolute currents as well as the increase of polarization resistance of X70 with increasing the exposure time. On the other hand, the pitting corrosion was found to increase with increasing the immersion time. This was confirmed by the increase of current with time and by the SEM images that were obtained on the steel surface after $20 \mathrm{~h}$ immersion before applying an amount of $0-.35 \mathrm{~V}$ versus $\mathrm{Ag} / \mathrm{AgCl}$ for $1 \mathrm{~h}$.
\end{abstract}

\section{Introduction}

API X70 pipeline steel is characterized by its good combination of strength and toughness, good weldability, low crack sensitivity coefficient, and low ductile to brittle transition temperature [1]. Therefore, several studies [1-5] have been conducted on the corrosion and corrosion protection of X70 pipeline steel in different aggressive media. Alizadeh and Bordbar have [1] reported the influence of microstructure on the protective properties of the corrosion product layer generated on the welded API X70 steel in sodium chloride solutions and found that the corrosion resistance for the steel was increased after heat treatment due to formation of fine and compact corrosion product layer with fewer defects. Bordbar and Alizadeh [2] also investigated the effects of microstructure alteration on corrosion behavior of welded joint in API X70 pipeline steel. Li et al. [3] studied the anodic dissolution of the $\mathrm{X} 70$ steel in $\mathrm{H}_{3} \mathrm{PO}_{4}$ solution with the halide ion perturbation at the interface and reported that the way how the halide ions affect the anodic dissolution is related to the types of the ions and the property of the film formed on the surface of the electrode. The corrosion of welded X70 pipeline steel in near-neutral $\mathrm{pH}$ solution was also characterized by Zhang and Cheng [4] using the microelectrochemical technique and confirmed that the resistance of corrosion product layer of the steel decreases with hydrogen charging and heat-affected zone has the largest dissolution current upon hydrogen charging. Furthermore, Sirong et al. [5] have invented a new method for preparing bionic multiscale superhydrophobic functional surface on X70 pipeline steel.

It is generally believed that general and pitting corrosion of passivated pipeline steel often occur when this steel is in contact with aggressive ions such as the chloride ions. In this regard, the corrosion of steel in various media such as carbonate/bicarbonate solution [6-9] and acidic solutions 
$[3,10,11]$ has been reported. Some other investigators have focused their studies on the corrosion of steels under disbanded coating [12-14] and hydrogen damage [15]. Although there are a lot of investigations on the corrosion of API X70 pipeline steel, the corrosion of this steel in Arabian Gulf seawater (AGSW) has not yet been reported to the best of our knowledge. The aim of this work was to investigate the corrosion of API X70 pipeline steel after its immersion in the freely aerated AGSW for different exposure periods, namely, $1 \mathrm{~h}$ and $20 \mathrm{~h}$, using varied electrochemical techniques such as potential-time, electrochemical impedance spectroscopy, cyclic polarization, and potentiostatic currenttime measurements along with scanning electron microscopy investigations. A particular attention was paid to the effect of immersion time on the pitting corrosion of the API X70 pipeline steel.

\section{Materials and Methods}

2.1. Materials and Chemicals. API X70 pipeline steel with a rectangular shape and dimension of $1 \mathrm{~cm}$ length and $1 \mathrm{~cm}$ width was employed in this study. The main chemical compositions for this steel were $0.04 \%$ C, $1.70 \% \mathrm{Mn}, 0.035 \%$ $S_{\max }, 0.035 \% P_{\max }$, and $0.55 \% \mathrm{Si}_{\max }$; all these elements were in mass percent. Arabian Gulf seawater was brought from the Arabian Gulf at Dammam, Saudi Arabia.

2.2. Electrochemical Corrosion Measurements. The electrochemical measurements were collected using a conventional electrochemical cell with a three-electrode configuration. The API X70 pipeline steel rod, a platinum foil, and an $\mathrm{Ag} / \mathrm{AgCl}$ electrode (in saturated $\mathrm{KCl}$ solution) were the working, counter, and reference electrodes, respectively. Before measurements, the surface of the working electrode was ground successively with metallographic emery paper of increasing fineness up to 1200 grit; it was then cleaned using doubly distilled water, degreased with acetone, washed using doubly distilled water again, and finally dried with dry air.

The electrochemical measurements were carried out using an Autolab Potentiostat (PGSTAT20 computer controlled) operated by the general purpose electrochemical software (GPES) version 4.9. The electrochemical impedance spectroscopy (EIS) tests were performed at open-circuit potential (OCP) over a frequency range of $100 \mathrm{kHz}$ to $100 \mathrm{mHz}$, with an ac wave of $\pm 5 \mathrm{mV}$ peak-to-peak overlaid on a dc bias potential, and the impedance data were collected using Powersine software at a rate of 10 points per decade change in frequency. The cyclic potentiodynamic polarization curves were obtained between -1.2 and 0.25 potential rang at a scan rate of $1 \mathrm{mV} / \mathrm{s}$ versus $\mathrm{Ag} / \mathrm{AgCl}$. Potentiostatic current-time experiments were carried out by stepping the potential of the steel samples at $-0.350 \mathrm{~V}$ versus $\mathrm{Ag} / \mathrm{AgCl}$. All experiments were carried out using a fresh electrode surface at room temperature in a cell that contains $200 \mathrm{~mL}$ of the test solutions.

2.3. Scanning Electron Microscope (SEM) Investigations. The SEM images were obtained by using a JEOL model JSM6610LV (Japanese made) scanning electron microscope with

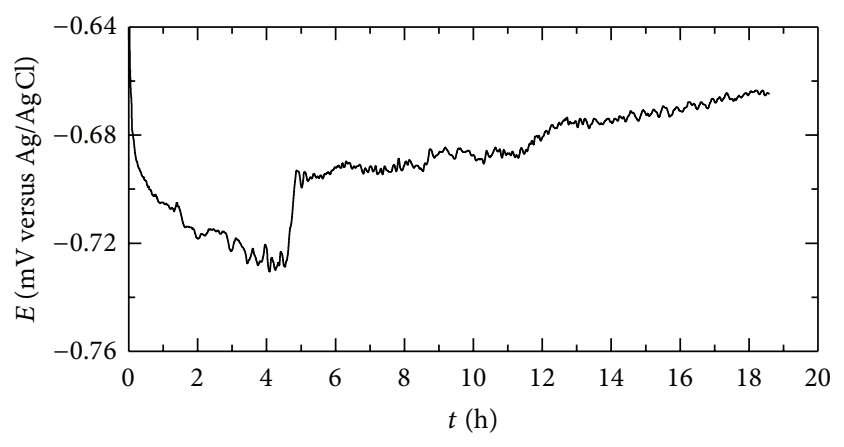

FIGURE 1: Change of the open-circuit potential versus time for the API X70 pipeline steel in Arabian Gulf seawater.

an energy dispersive $\mathrm{X}$-ray analyzer attached for acquiring the EDX analysis.

\section{Results and Discussion}

3.1. Open-Circuit Potential (OCP) Measurements. Figure 1 shows the variation of the potential of API X70 pipeline steel in AGSW against time for circa $20 \mathrm{~h}$. It is seen that the potential of the steel in AGSW increased towards the more negative values from the first moment of electrode immersion, which resulted from the dissolution of an air oxide film which was formed on the steel surface before its immersion. The potential further decreased in the more negative direction due to the continuous dissolution of the steel surface under the aggressiveness action of the anions present in the AGSW. After about $4 \mathrm{~h}$, the steel potential abruptly shifted in the less negative direction indicating that the steel surface developed an oxide film and/or corrosion product layer that could provide certain protection and decreased the corrosive attack of the AGSW on the surface. The potential then continued shifting in the less negative direction with time till the end of the run. This was due to the oxide film and/or corrosion product thickening with time, which provided more protection for the steel surface and led to the increase of potential towards the less negative values.

\subsection{Electrochemical Impedance Spectroscopy (EIS) Measure-} ments. Figure 2 shows the EIS Nyquist plots obtained for the API X70 pipeline steel after its immersion for (a) 1 hour and (b) $20 \mathrm{~h}$ in Arabian Gulf seawater. The data obtained from Figure 2 were best fitted to the equivalent circuit model depicted in Figure 3. The values of the elements of the equivalent circuit shown in Figure 3 are listed in Table 1, where $R_{S}$ represents the solution resistance, $Q$ the constant phase elements (CPEs), and $R_{P}$ the polarization resistance [16-19].

It is clearly seen from Figure 2 that there is only one semicircle whether the immersion time was $1 \mathrm{~h}$ or $20 \mathrm{~h}$. The diameter of the semicircle is higher for the steel that was immersed for $20 \mathrm{~h}$, curve (b), than that obtained after $1 \mathrm{~h}$. This indicates that increasing the immersion time decreases the aggressiveness action of the AGSW towards the steel, which is due to the fact that the increased immersion time allows 
TABLE 1: EIS parameters obtained by fitting the Nyquist plots shown in Figure 2 with the equivalent circuit shown in Figure 3 for X70 steel after $1 \mathrm{~h}$ and $20 \mathrm{~h}$ immersion in Arabian Gulf seawater.

\begin{tabular}{lcccc}
\hline \multirow{2}{*}{ Medium } & \multicolumn{2}{c}{ Parameter } & & \\
& $R_{S}\left(\Omega \mathrm{cm}^{2}\right)$ & $Y_{\mathrm{Q}} / \mathrm{F} \mathrm{cm}^{-2}$ & $R_{P}\left(\Omega \mathrm{cm}^{2}\right)$ \\
\hline AGSW $(1 \mathrm{~h})$ & 12.24 & 0.001433 & 0.78 & 839 \\
AGSW $(20 \mathrm{~h})$ & 13.12 & 0.0001047 & 0.80 & 1025 \\
\hline
\end{tabular}

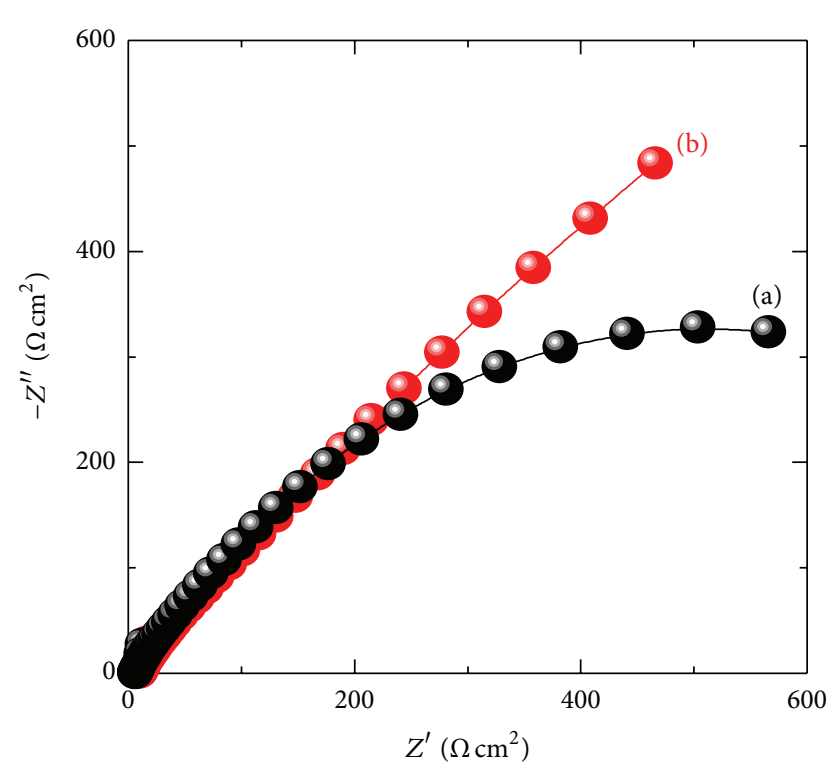

FIGURE 2: EIS Nyquist plots obtained for the API X70 pipeline steel after its immersion for (a) $1 \mathrm{~h}$ and (b) $20 \mathrm{~h}$ in Arabian Gulf seawater.

the surface to develop a corrosion product layer and/or an oxide film that gets thicker with time and provides some protection to the surface against corrosion. This was also confirmed by the data recorded in Table 1 , where the $R_{S}$ and $R_{P}$ values are higher for the steel that was immersed for $20 \mathrm{~h}$ in AGSW before measurements. The constant phase elements (CPEs, $Q$ ) with their $n$ values are around 0.8; CPEs thus represent double layer capacitors because their $n$ values are close to unity. The value of $Q$ decreased with increasing time, which proves that the mass transport from surface is limited, particularly after $20 \mathrm{~h}$ of the steel immersion in the AGSW [20-22]. According to Arzola-Peralta et al. [23], who studied the corrosion of X70 pipeline steel at similar conditions, at high frequencies a transfer process takes place. This emphasizes the fact that increasing the immersion time before measurements decreases the corrosion of the steel, which can result from the formation of an oxide film and/or corrosion products that could partially protect the surface from being attacked by the chloride ions present in solutions under investigations.

The data obtained from Nyquist plots were also confirmed by the Bode impedance and Bode phase angle plots that are shown in Figures 4 and 5, respectively, for the API X70 pipeline steel electrode after its immersion in AGSW for (a) $1 \mathrm{~h}$ and (b) $20 \mathrm{~h}$. Figure 4 depicts that the impedance of the

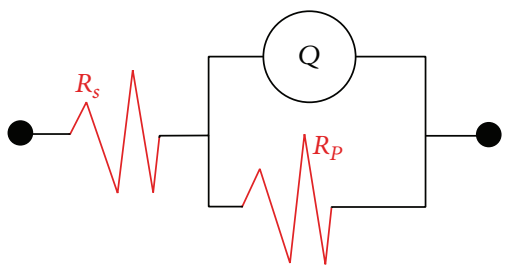

FIGURE 3: The equivalent circuit model used to fit the experimental data presented by Nyquist plots shown in Figure 2; symbols of the circuit are defined in the text.

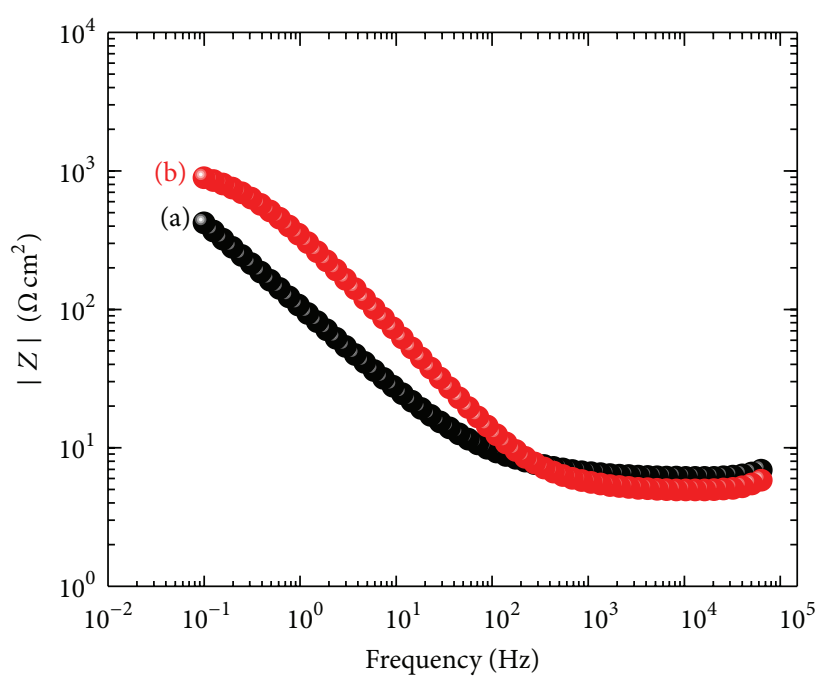

FIGURE 4: Bode impedance plots obtained for the API X70 pipeline steel after its immersion for (a) $1 \mathrm{~h}$ and (b) $20 \mathrm{~h}$ in Arabian Gulf seawater.

interface for the X70 increases with increasing the immersion time from $1 \mathrm{~h}$ to $20 \mathrm{~h}$, particularly at lower frequency values. According to Mansfeld et al. [22], the high impedance values at the low frequency region confirms the passivation of the surface. This indicates that the increase of the immersion time from $1 \mathrm{~h}$ to $20 \mathrm{~h}$ increases the corrosion resistance of the steel in AGSW through increasing the passivity of its surface. Figure 5 also showed that the increase of the immersion time from $1 \mathrm{~h}$ to $20 \mathrm{~h}$ before measurements increased the maximum degree of the phase angle, which gives further confirmation on the increased surface passivity with increased exposure intervals.

3.3. Cyclic Potentiodynamic Polarization (CPP) Data. The CPP curves obtained for API X70 pipeline steel after its 
TABLE 2: Parameters obtained from cyclic potentiodynamic polarization curves shown in Figure 6 for X70 steel after $1 \mathrm{~h}$ and $20 \mathrm{~h}$ immersion in Arabian Gulf seawater.

\begin{tabular}{lcccccccc}
\hline \multirow{2}{*}{ Medium } & \multicolumn{1}{c}{ Parameter } \\
& $E_{\text {Corr }}(\mathrm{mV})$ & $j_{\text {Corr }}\left(\mu \mathrm{Acm}^{-2}\right)$ & $\beta_{c}\left(\mathrm{mV} \mathrm{dec}^{-1}\right)$ & $\beta_{a}\left(\mathrm{mV} \mathrm{dec}^{-1}\right)$ & $E_{\text {Pit }}(\mathrm{mV})$ & $E_{\text {Prot }}(\mathrm{mV})$ & $R_{p}\left(\mathrm{k} \Omega \mathrm{cm}^{2}\right)$ & $R_{\mathrm{Corr}}\left(\mathrm{mmy}^{-1}\right)$ \\
\hline AGSW (1h) & -850 & 16 & 95 & 450 & -450 & -600 & 2.13 & 0.167 \\
AGSW (20 h) & -860 & 13 & 100 & 200 & -375 & -575 & 2.22 & 0.151 \\
\hline
\end{tabular}

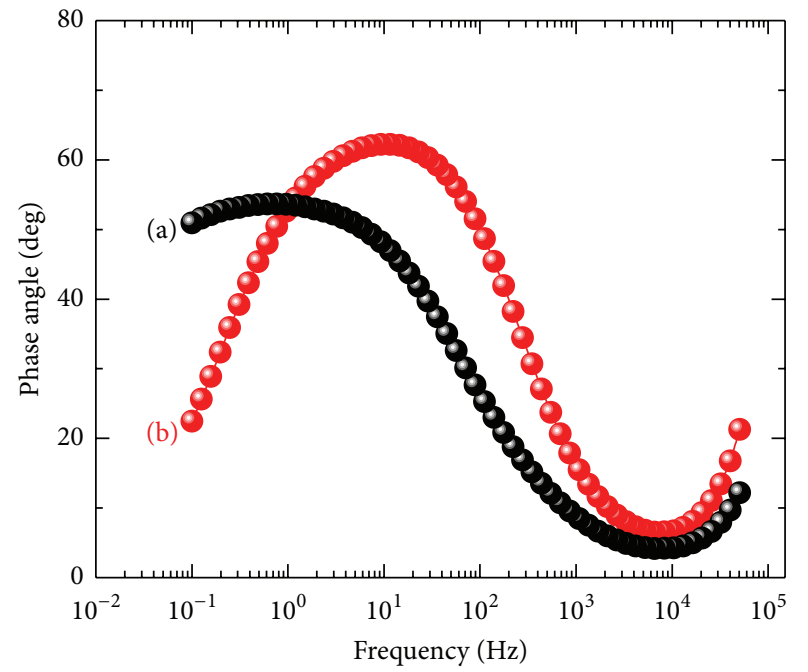

FIGURE 5: Bode phase angle plots obtained for the API X70 pipeline steel after its immersion for (a) $1 \mathrm{~h}$ and (b) $20 \mathrm{~h}$ in Arabian Gulf seawater.

immersion for (a) $1 \mathrm{~h}$ and (b) $20 \mathrm{~h}$ in the Arabian Gulf seawater are shown, respectively, in Figure 6. These curves were collected in order to understand the change of current with potential and to report the corrosion parameters for the API X70 steel after varied exposure intervals in AGSW. The values of the corrosion parameters such as cathodic $\left(\beta_{c}\right)$ and anodic $\left(\beta_{a}\right)$ Tafel slope, corrosion potential $\left(E_{\mathrm{Corr}}\right)$, corrosion current density $\left(j_{\text {Corr }}\right)$, pitting potential $\left(E_{\text {Pit }}\right)$, pitting current density $\left(j_{\text {Pit }}\right)$, protection potential $\left(E_{\text {Prot }}\right)$, polarization resistance $\left(R_{p}\right)$, and corrosion rate $\left(R_{\text {Corr }}\right)$ obtained for the API X70 steel electrodes from the CPP curves shown in Figure 6 are listed in Table 2. The values of all these parameters were obtained as reported in the previous studies [16-19].

It has been reported [24-28] that the cathodic reaction of metals and alloys in an open to air near neutral solution is the oxygen reduction. On the other hand, the anodic reaction takes place via the dissolution of iron from $\mathrm{Fe}(0)$ to Fe(II). According to Alizadeh and Bordbar [1], the cathodic and anodic reactions can be represented, respectively, as follows:

$$
\begin{gathered}
\mathrm{O}_{2}+2 \mathrm{H}_{2} \mathrm{O}+4 \mathrm{e} \rightleftarrows 4 \mathrm{OH}^{-} \\
\mathrm{Fe} \rightleftarrows \mathrm{Fe}^{2+}+2 \mathrm{e}
\end{gathered}
$$

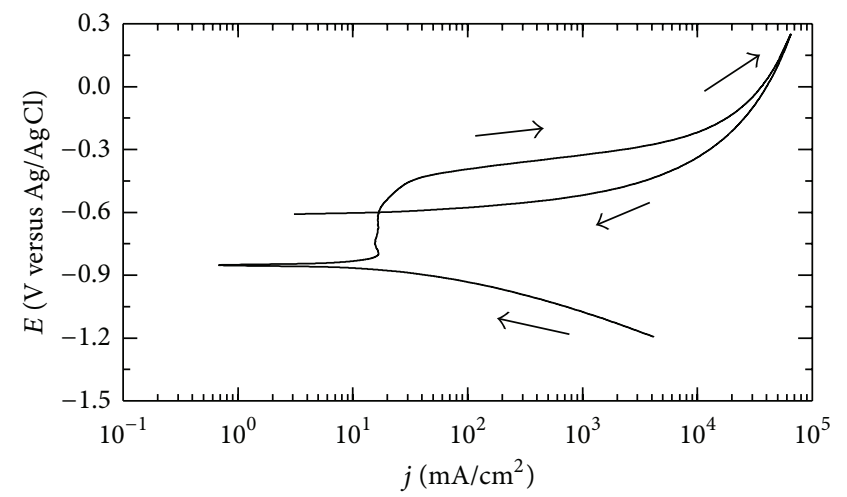

(a)

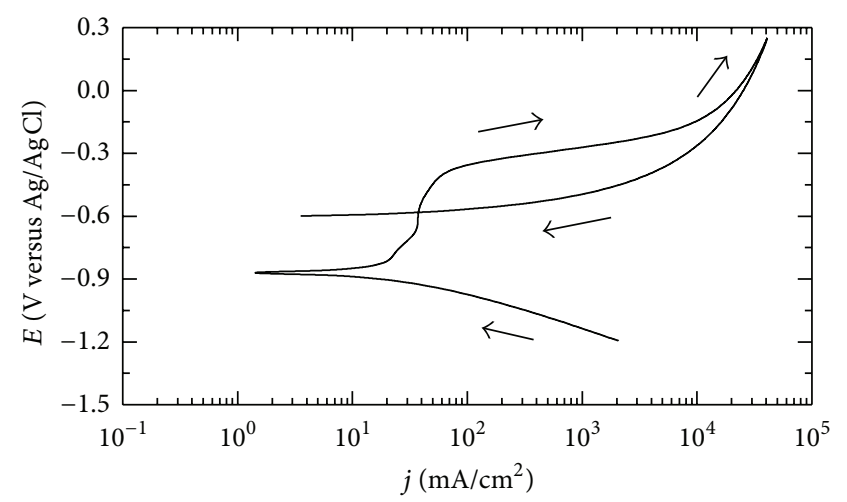

(b)

FIGURE 6: Cyclic potentiodynamic polarization curves obtained for API X70 pipeline steel after its immersion for (a) $1 \mathrm{~h}$ and (b) $20 \mathrm{~h}$ in the Arabian Gulf seawater.

In the chloride containing carbonate/bicarbonate, which is the case of the natural seawater, AGSW, the $\mathrm{FeCO}_{3}$ can be formed and deposited on the steel surface as follows [1]:

$$
\begin{gathered}
\mathrm{Fe}^{2+}+\mathrm{CO}_{3}{ }^{2-} \rightleftarrows \mathrm{FeCO}_{3} \\
\mathrm{Fe}+\mathrm{HCO}_{3}{ }^{-}+\mathrm{e} \rightleftarrows \mathrm{FeCO}_{3}+\mathrm{H}
\end{gathered}
$$

Fu and Cheng [29] have also reported that the formation and the deposition of $\mathrm{FeCO}_{3}$ provide an inhibition for the steel surface from further dissolution.

It is clearly seen from Figure 6 that the X70 pipeline steel shows an active-passive anodic behavior, where the steel forms a passive region in the potential range between -800 and $-400 \mathrm{mV}$ for the steel in the AGSW solution; the appearance of such region is due to the formation of an oxide film and/or corrosion products. At these conditions, 
the corrosion products might be iron carbonate and chloride compounds such as $\mathrm{FeCO}_{3}, \mathrm{FeCl}_{2}$, and $\mathrm{FeOCl}$ and the oxides can be $\mathrm{Fe}_{3} \mathrm{O}_{4}$ and $\mathrm{Fe}_{2} \mathrm{O}_{3}[1]$. The formation of such oxides can be represented as follows [30]:

$$
\begin{aligned}
& 4 \mathrm{FeCO}_{3}+\mathrm{O}_{2}+4 \mathrm{H}_{2} \mathrm{O} \rightleftarrows 2 \mathrm{Fe}_{2} \mathrm{O}_{3}+4 \mathrm{HCO}_{3}{ }^{-}+4 \mathrm{H}^{+} \\
& 6 \mathrm{FeCO}_{3}+\mathrm{O}_{2}+6 \mathrm{H}_{2} \mathrm{O} \rightleftarrows 2 \mathrm{Fe}_{3} \mathrm{O}_{4}+6 \mathrm{HCO}_{3}{ }^{-}+6 \mathrm{H}^{+}
\end{aligned}
$$

Increasing the applied potential in the less negative direction leads to increasing the output current due to the dissolution of the formed passive film and the occurrence of pitting corrosion. Reversing the potential in the backward scan resulted in an increase in the output current and the appearance of a hysteresis loop, which indicates the occurrence of pitting corrosion for the API X70 steel in the AGSW test medium. Table 2 also indicated that the $j_{\text {Corr }}$, anodic current, and $R_{\text {Corr }}$ recorded higher values, while the $\left(R_{p}\right)$ is lower for the steel in AGSW after $1 \mathrm{~h}$ immersion. Increasing the immersion time from $1 \mathrm{~h}$ to $20 \mathrm{~h}$ decreased the values of $j_{\text {Corr }}$ and $R_{\text {Corr }}$ and increased the values of $\left(R_{p}\right)$. This also agrees with the impedance data that the corrosion of API X70 steel decreases with increasing the immersion time before measurements.

\subsection{Potentiostatic Current-Time and Scanning Electron} Microscopy Investigations. The variation of the potentiostatic current versus time at $-0.350 \mathrm{mV}$ versus $\mathrm{Ag} / \mathrm{AgCl}$ after (a) $1 \mathrm{~h}$ and (b) $20 \mathrm{~h}$ in AGSW is shown in Figure 7. These experiments were carried out to report the anodic dissolution of the API X70 steel at an active anodic potential and to see whether pitting corrosion occurs after varied exposure periods in the test solution. The current of the steel after $1 \mathrm{~h}$ immersion in AGSW, curve (a), recorded very high value that increased in the first few seconds before decreasing again till the first $400 \mathrm{~s}$. The increase of current might have resulted from the dissolution of an oxide film which was formed on the surface due to the contact with the solution. On the other hand, the decrease in the current values was either due to the formation of an oxide and/or corrosion products film that decreases the effect of the aggressiveness action of the test solution. The current then shows almost a stable change with increasing time up to the end of the run.

Increasing the immersion time to $20 \mathrm{~h}$ before measurements could decrease the initial currents for steel in the AGSW solution to its minimum due to the formation of corrosion products and/or passive film on the electrode surface during its immersion before applying the constant potential. The current then gradually increases with increasing the time of the experiment as a result of the dissolution of the formed passive film and the occurrence of pitting corrosion. This can be also explained by the dissolution of iron as represented by (2) and then the formation of $\mathrm{FeCl}_{2}$ and $\mathrm{FeCl}_{3}$ on the surface of the steel according to the following reactions [31, 32]:

$$
\begin{aligned}
& \mathrm{Fe}_{(\mathrm{s})}+2 \mathrm{Cl}_{(\mathrm{aq})}^{-} \rightleftarrows \mathrm{FeCl}_{2(\mathrm{~s})}+2 \mathrm{e}^{-} \\
& \mathrm{FeCl}_{2(\mathrm{~s})}+\mathrm{Cl}^{-}(\mathrm{aq}) \rightleftarrows \mathrm{FeCl}_{3(\mathrm{~s})}+\mathrm{e}^{-}
\end{aligned}
$$

Due to the applied potential and concentration gradients, the $\mathrm{FeCl}_{2}$ and $\mathrm{FeCl}_{3}$ species at the interface diffuse through the

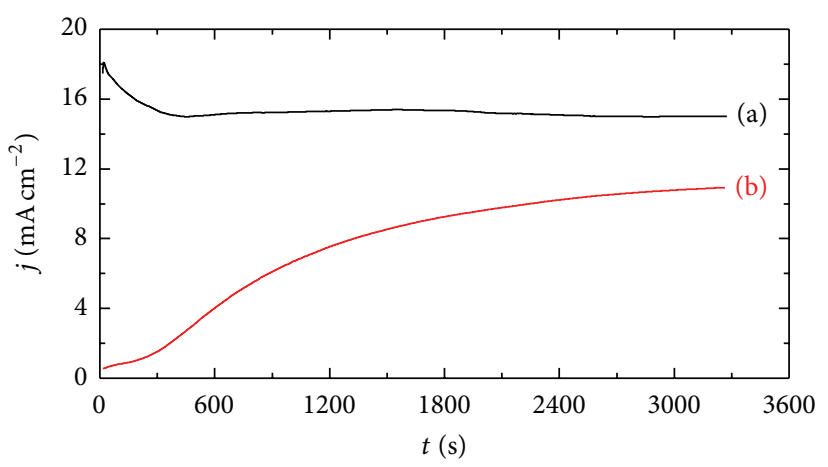

Figure 7: Potentiostatic current-time curves obtained at $-0.35 \mathrm{~V}$ versus $\mathrm{Ag} / \mathrm{AgCl}$ for the API X70 pipeline steel electrode after (a) 1 hour and (b) $20 \mathrm{~h}$ immersions in the Arabian Gulf seawater.

porous film and the diffusion boundary layer and are then carried away to the bulk solution leading to a continuous dissolution of the alloy and the occurrence of pitting corrosion as indicated by the continuous increase of the current with time.

This was confirmed by the SEM micrographs obtained for the API X70 pipeline steel surface after performing the current-time experiment shown in Figure 7 (curve (b)). Figure 8 shows the SEM micrographs obtained for the API X70 pipeline steel surface after its immersion for $20 \mathrm{~h}$ then applying $-0.35 \mathrm{mV}$ for $1 \mathrm{~h}$, which shows an increased magnification for the steel surface. Figure 8(a) depicts that the majority of the steel surface has few pits and some of these pits were propagated and could lead to the continuous increase of the current with time which we have seen on curve (b) of Figure 7. Figures 8(b) and 8(c) show clear images of the propagated pits and prove that the increase of current with time at $-0.35 \mathrm{~V}$ was due to the occurrence of pitting corrosion. The data obtained by potentiostatic current-time thus confirm the data obtained by EIS and polarization measurements that increasing the immersion time of the API X70 pipeline steel decreases the uniform corrosion and increases the pitting one.

\section{Conclusion}

The corrosion of API X70 pipeline steel after $1 \mathrm{~h}$ and $20 \mathrm{~h}$ immersion in Arabian Gulf seawater (AGSW) has been reported using variety of electrochemical measurements. Potential-time experiments indicated that the potential of the steel shifts to the more negative values in the first few minutes of the immersion and then forms a layer of oxides and/or corrosion products that partially protect the steel surface and shift its potential towards the less negative values with time. Electrochemical impedance spectroscopy data revealed that X70 steel shows one semicircle in AGSW solution and increasing the immersion time to $20 \mathrm{~h}$ increases the surface and polarizations resistances. Cyclic polarization technique confirmed that the steel shows lower corrosion current and corrosion rate and higher polarization resistance in AGSW with the increase of the immersion time from $1 \mathrm{~h}$ to $20 \mathrm{~h}$, 

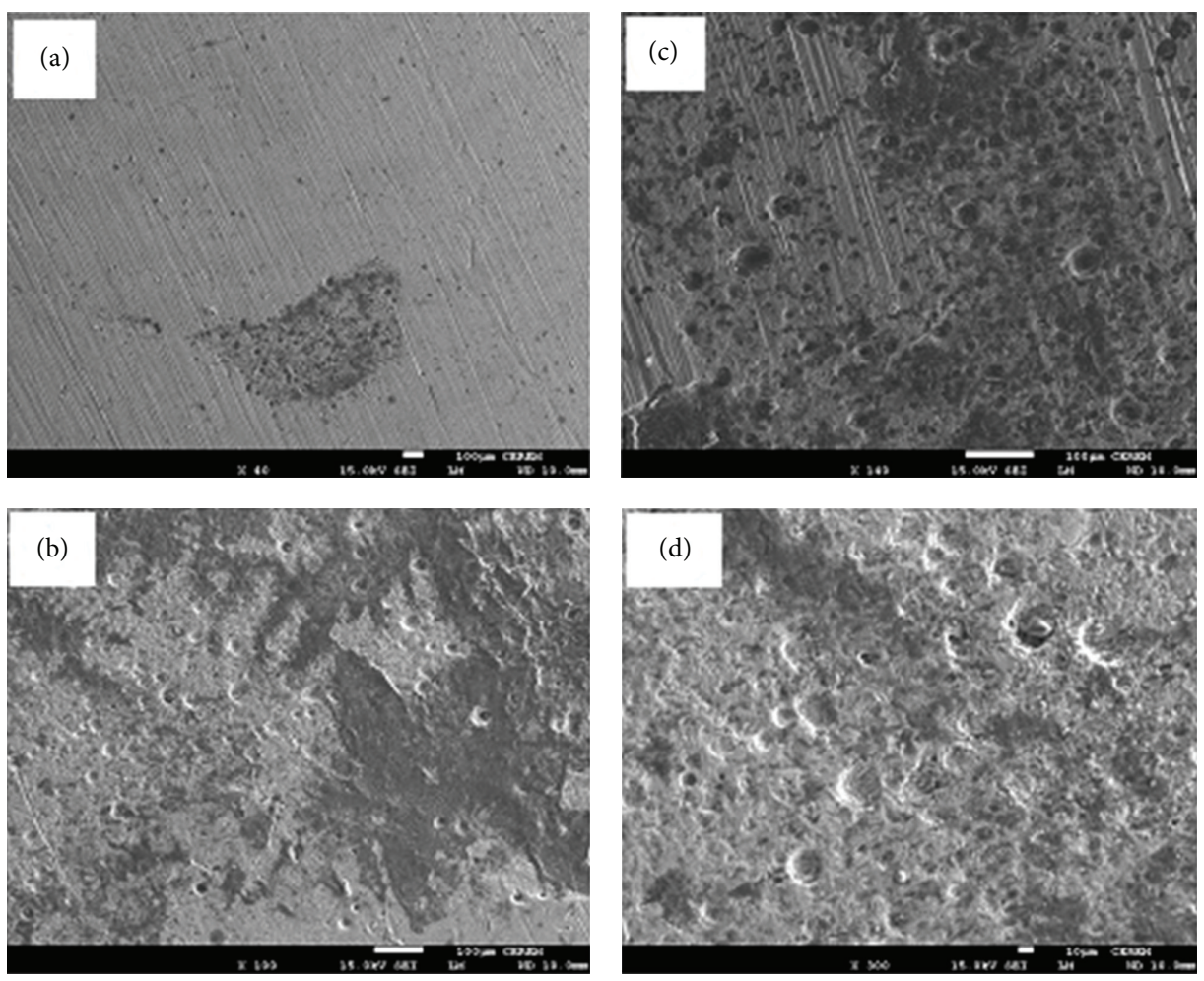

FIGURE 8: SEM micrographs obtained on the API X70 pipeline steel electrode after its immersion for $20 \mathrm{~h}$ in the Arabian Gulf seawater then stepping the potential to $-0.35 \mathrm{~V}$ versus $\mathrm{Ag} / \mathrm{AgCl}$ for $1 \mathrm{~h}$.

which indicates that the general corrosion decreases and the pitting corrosion increases. Potentiostatic current-time experiments at $-0.35 \mathrm{mV}$ versus $\mathrm{Ag} / \mathrm{AgCl}$ indicated that the X70 steel confirmed the data obtained by EIS and polarization measurements that the current recorded higher values with $1 \mathrm{~h}$ exposure period. On the other hand, increasing the time to $20 \mathrm{~h}$ decreased the absolute currents of the steel, where the initial currents were very low and increased with increasing the time of the applied potential. All measurements thus were consistent with each other and proved that the increase of the immersion time of the API X70 steel in the AGSW solution before measurements decreases the uniform corrosion through decreasing the absolute current values, while it increases the pitting corrosion by increasing the current with time.

\section{Conflict of Interests}

The authors declare that there is no conflict of interests regarding the publication of this paper.

\section{Acknowledgment}

The authors extend their appreciation to the Deanship of Scientific Research at KSU for funding the work through the research group Project no. RGP-VPP-160.

\section{References}

[1] M. Alizadeh and S. Bordbar, "The influence of microstructure on the protective properties of the corrosion product layer generated on the welded API X70 steel in chloride solution," Corrosion Science, vol. 70, p. 170, 2013.

[2] S. Bordbar and M. Alizadeh, "Effects of microstructure alteration on corrosion behavior of welded joint in API X70 pipeline steel," Materials and Design, vol. 45, p. 597, 2013.

[3] L. Li, C. Wang, and H. Lu, "Anodic dissolution of the X70 steel in $\mathrm{H}_{3} \mathrm{PO}_{4}$ solution with the halide-ion perturbation at the interface," Electrochimica Acta, vol. 104, p. 295, 2013.

[4] G. A. Zhang and Y. F. Cheng, "Micro-electrochemical characterization of corrosion of welded X70 pipeline steel in near-neutral pH solution," Corrosion Science, vol. 51, no. 8, pp. 1714-1724, 2009.

[5] Y. Sirong, W. Xiaolong, W. Wei, Y. Qiang, X. Jun, and X. Wei, "A new method for preparing bionic multi scale superhydrophobic functional surface on X70 pipeline steel," Applied Surface Science, vol. 271, p. 149, 2013.

[6] M. Torabi Merajin, S. Sharifnia, S. N. Hosseini, and N. Yazdanpour, "Photocatalytic conversion of greenhouse gases $\left(\mathrm{CO}_{2}\right.$ and $\mathrm{CH}_{4}$ ) to high value products using $\mathrm{TiO}_{2}$ nanoparticles supported on stainless steel webnet," Journal of the Taiwan Institute of Chemical Engineers, vol. 44, p. 239, 2013.

[7] A. A. Oskuie, T. Shahrabi, A. Shahriari, and E. Saebnoori, "Electrochemical impedance spectroscopy analysis of X70 pipeline steel stress corrosion cracking in high $\mathrm{pH}$ carbonate solution," Corrosion Science, vol. 61, p. 111, 2012. 
[8] S.-Y. Zhao, S.-H. Chen, H.-Y. Ma, D.-G. Li, and F.-J. Kong, "Current oscillations during electrodissolution of iron in perchloric acid solutions," Journal of Applied Electrochemistry, vol. 32, no. 2, pp. 231-235, 2002.

[9] Z. Y. Liu, X. G. Li, C. W. Du, and Y. F. Cheng, "Local additional potential model for effect of strain rate on SCC of pipeline steel in an acidic soil solution," Corrosion Science, vol. 51, no. 12, pp. 2863-2871, 2009.

[10] S. Alarmal Mangai and S. Ravi, "Comparative corrosion inhibition effect of imidazole compounds and of Trichodesma indicum (Linn) R. Br. on C38 steel in $1 \mathrm{M} \mathrm{HCl}$ medium," Journal of Chemistry, vol. 2013, Article ID 527286, 4 pages, 2013.

[11] D. Sazou and M. Pagitsas, "Nitrate ion effect on the passive film breakdown and current oscillations at iron surfaces polarized in chloride-containing sulfuric acid solutions," Electrochimica Acta, vol. 47, no. 10, pp. 1567-1578, 2002.

[12] A. Q. Fu, X. Tang, and Y. F. Cheng, "Characterization of corrosion of X70 pipeline steel in thin electrolyte layer under disbonded coating by scanning Kelvin probe," Corrosion Science, vol. 51, no. 1, pp. 186-190, 2009.

[13] M. Yan, J. Wang, E. Han, and W. Ke, "Local environment under simulated disbonded coating on steel pipelines in soil solution," Corrosion Science, vol. 50, no. 5, pp. 1331-1339, 2008.

[14] J. Min, J. H. Park, H.-K. Sohn, and J. M. Park, "Synergistic effect of potassium metal siliconate on silicate conversion coating for corrosion protection of galvanized steel," Journal of Industrial and Engineering Chemistry, vol. 18, no. 2, pp. 655-660, 2012.

[15] H. C. Genuino, N. N. Opembe, E. C. Njagi, S. McClain, and S. L. Suib, "A review of hydrofluoric acid and its use in the car wash industry," Journal of Industrial and Engineering Chemistry, vol. 18, p. 1529, 2012.

[16] E. M. Sherif and S.-M. Park, "Inhibition of copper corrosion in $3.0 \% \mathrm{NaCl}$ solution by $\mathrm{N}$-phenyl-1,4-phenylenediamine," Journal of the Electrochemical Society, vol. 152, no. 10, pp. B428B433, 2005.

[17] E. M. Sherif and S.-M. Park, "Effects of 2-amino-5-ethylthio1,3,4-thiadiazole on copper corrosion as a corrosion inhibitor in aerated acidic pickling solutions," Electrochimica Acta, vol. 51, no. 28, pp. 6556-6562, 2006.

[18] E. M. Sherif and S.-M. Park, "Inhibition of copper corrosion in acidic pickling solutions by N-phenyl-1,4-phenylenediamine," Electrochimica Acta, vol. 51, no. 22, pp. 4665-4673, 2006.

[19] E. M. Sherif and S.-M. Park, "2-Amino-5-ethyl-1,3,4-thiadiazole as a corrosion inhibitor for copper in $3.0 \% \mathrm{NaCl}$ solutions," Corrosion Science, vol. 48, no. 12, pp. 4065-4079, 2006.

[20] J. R. Macdonald, Impedance Spectroscopy, John Wiley \& Sons, New York, NY, USA, 1987.

[21] P. C. Okafor, C. B. Liu, X. Liu et al., "Corrosion inhibition and adsorption behavior of imidazoline salt on N80 carbon steel in $\mathrm{CO}_{2}$-saturated solutions and its synergism with thiourea," Journal of Solid State Electrochemistry, vol. 14, no. 8, pp. 13671376, 2010.

[22] F. Mansfeld, S. Lin, K. Kim, and H. Shih, "Pitting and surface modification of SIC/Al," Corrosion Science, vol. 27, no. 9, pp. 997-1000, 1987.

[23] S. Arzola-Peralta, J. Genesca-Llongueras, J. Mendoza-Flores, and R. Duran-Romero, "Corrosion behavior of X70 pipeline steel in $\mathrm{H}_{2} \mathrm{~S}$ containing solutions," in Proceedings of the Corrosion, NACE International, New Orleans, La, USA, April 2004.

[24] E. J. Calvo and N. Mozhzhukhina, "A rotating ring disk electrode study of the oxygen reduction reaction in lithium containing non aqueous electrolyte," Electrochemistry Communication, vol. 31, p. 56, 2013.

[25] V. P. Shinde and P. P. Patil, "A study on the electrochemical polymerization, characterization, and corrosion protection of o-toluidine on steel," Journal of Solid State Electrochemistry, vol. 19, p. 29, 2013.

[26] E.-S. M. Sherif, R. M. Erasmus, and J. D. Comins, "Corrosion of copper in aerated synthetic sea water solutions and its inhibition by 3-amino-1,2,4-triazole," Journal of Colloid and Interface Science, vol. 309, no. 2, pp. 470-477, 2007.

[27] M. El-Sayed Sherif, A. A. Almajid, K. A. Khalil, H. Junaedi, and F. H. Latief, "Electrochemical Studies on the Corrosion Behavior of API X65 Pipeline Steel in Chloride Solutions," International Journal of Electrochemical Science, vol. 8, p. 9360, 2013.

[28] E.-S. M. Sherif and A. H. Ahmed, "Synthesizing new hydrazone derivatives and studying their effects on the inhibition of copper corrosion in sodium chloride solutions," Synthesis and Reactivity in Inorganic, Metal-Organic and Nano-Metal Chemistry, vol. 40, no. 6, pp. 365-372, 2010.

[29] Q. A. Fu and Y. F. Cheng, "Electrochemical polarization behavior of X70 steel in thin carbonate/bicarbonate solution layers trapped under a disbonded coating and its implication on pipeline SCC," Corrosion Science, vol. 52, p. 2511, 2010.

[30] J. K. Heuer and J. F. Stubbins, "An XPS characterization of $\mathrm{FeCO}_{3}$ films from $\mathrm{CO}_{2}$ corrosion," Corrosion Science, vol. 41, no. 7, pp. 1231-1243, 1999.

[31] C. A. Melendres, N. Camillone III, and T. Tipton, "Laser raman spectroelectrochemical studies of anodic corrosion and film formation on iron in phosphate solutions," Electrochimica Acta, vol. 34, no. 2, pp. 281-286, 1989.

[32] J. L. Yao, B. Ren, Z. F. Huang, P. G. Cao, R. A. Gu, and Z.-Q. Tian, "Extending surface Raman spectroscopy to transition metals for practical applications IV. A study on corrosion inhibition of benzotriazole on bare Fe electrodes," Electrochimica Acta, vol. 48, no. 9, pp. 1263-1271, 2003. 

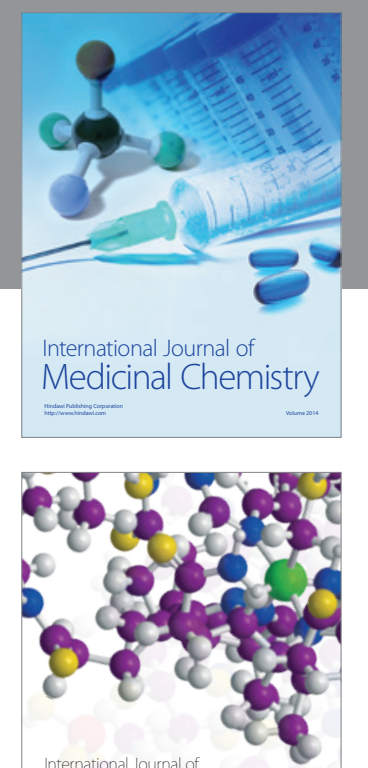

\section{Carbohydrate} Chemistry

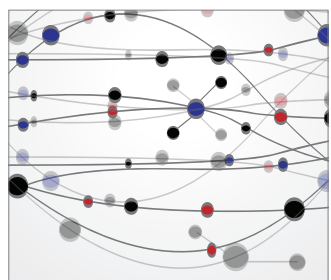

The Scientific World Journal
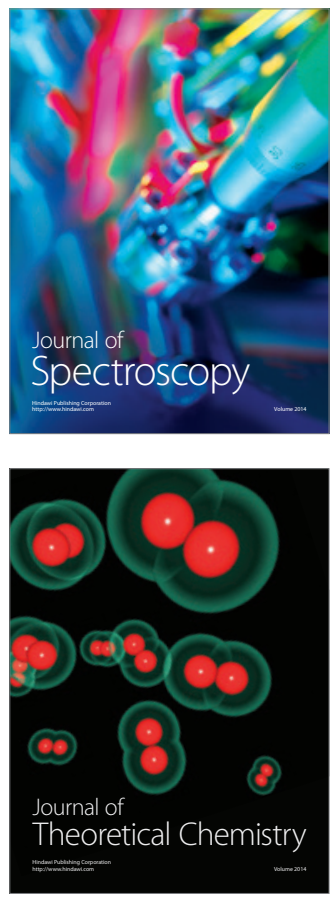
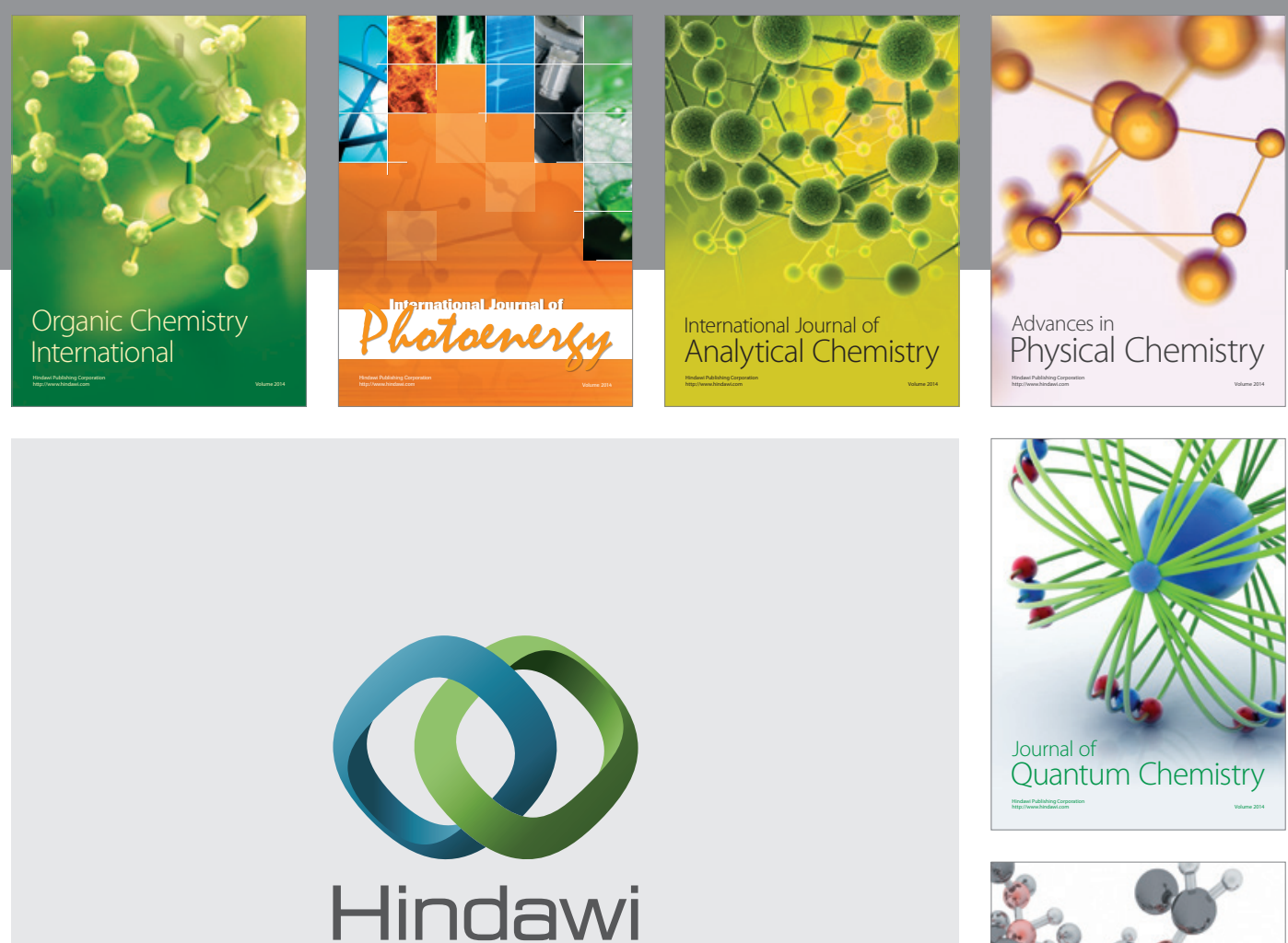

Submit your manuscripts at

http://www.hindawi.com

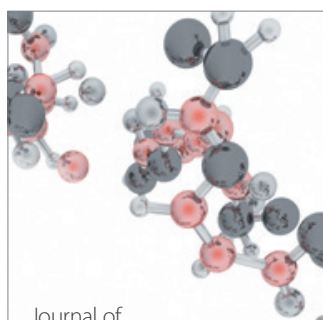

Analytical Methods

in Chemistry

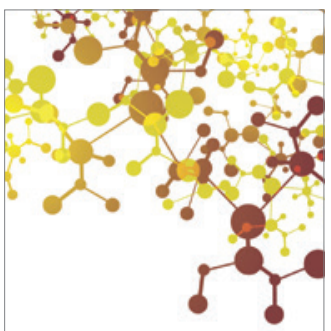

Journal of

Applied Chemistry

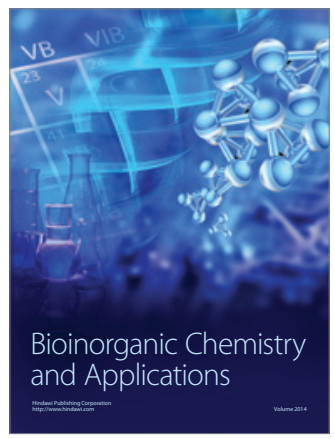

Inorganic Chemistry
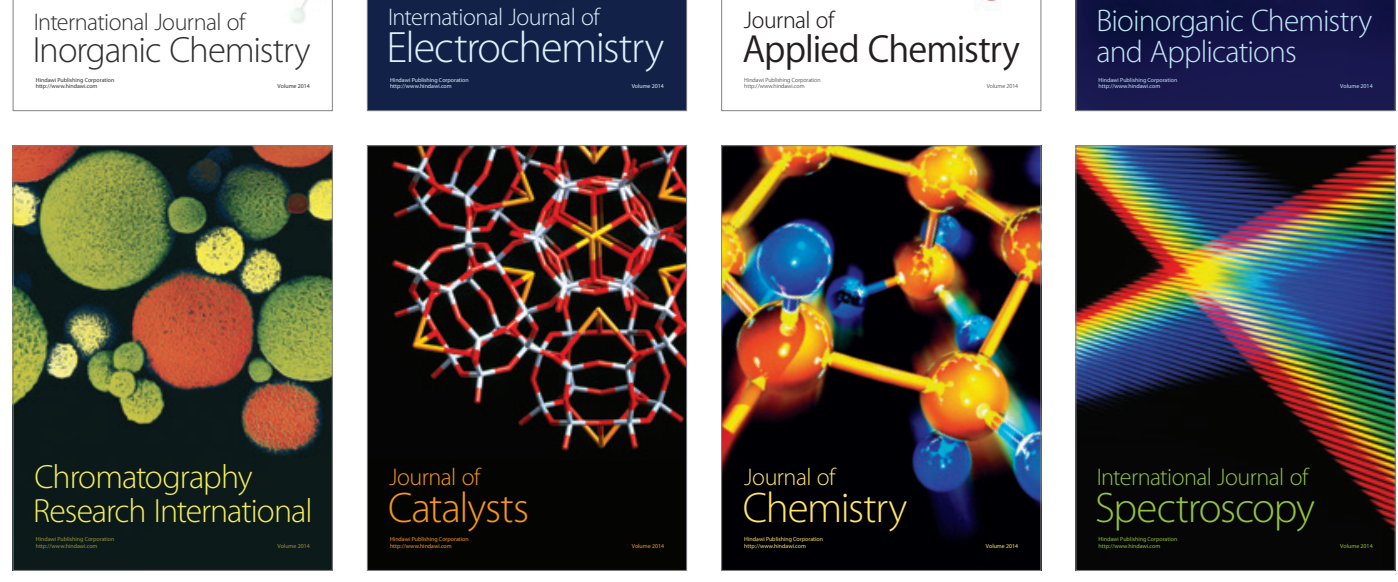